\title{
Adverse Event Outcome ICSR Terminology
}

National Cancer Institute

\section{Source}

National Cancer Institute. Adverse Event Outcome ICSR Terminology. NCI Thesaurus.

Code C54583.

Terminology used in Individual Case Safety Reports for description of adverse event outcomes, section B2 of FDA MedWatch Form. 